\title{
AN IMPORTANT PITFALL OF PSEUDO-STATIC FINITE ELEMENT ANALYSIS
}

S. Kontoe, L. Pelecanos \& D.M. Potts

\begin{abstract}
:
Finite Element (FE) pseudo-static analysis can provide a good compromise between simplified methods of dynamic analysis and time domain analysis. The pseudo-static FE approach can accurately model the in-situ stresses prior to seismic loading (when it follows a static analysis simulating the construction sequence) is relatively simple and not as computationally expensive as the time domain approach. However this method should be used with caution as the results can be sensitive to the choice of the mesh dimensions. In this paper two simple examples of pseudo-static finite element analysis are examined parametrically, a homogeneous slope and a cantilever retaining wall, exploring the sensitivity of the pseudo static analysis results on the adopted mesh size. The mesh dependence was found to be more pronounced for problems with high critical seismic coefficients values (e.g. gentle slopes or small walls), as in these cases a generalised layer failure mechanism is developed simultaneously with the slope or wall mechanism. In general the mesh width was found not to affect notably the predicted value of critical seismic coefficient but to have a major impact on the predicted movements.
\end{abstract}




\subsection{Introduction}

The seismic design of geotechnical structures often relies on simplified pseudo-static methods of analysis. For example, limit equilibrium (LE) based methods, like the Mononobe-Okabe method, are still widely used in engineering practice for the seismic design of retaining structures. These simple design procedures are straightforward, but they do not provide directly any indication of deformations under the design earthquake load. However during an earthquake, movements of both the soil and the structure will occur under seismic loading, regardless of how over-designed the structure may be. To get an estimate of the seismically induced movements the LE methods are usually combined with a sliding block type of analyses which have been shown to be very sensitive to the seismic coefficient obtained by the LE analysis (Crespellani et al 1998).

On the other hand, time domain analysis, using acceleration time histories, provides a rigorous tool for the safe and economic seismic design of a geotechnical structure, as it can give predictions of the performance of a structure under any given seismic scenario. However, this type of analysis requires the use of computational codes (Finite Element (FE) / Finite Difference) which encompass advanced constitutive models capable of simulating the response of soils to seismic loading and boundary conditions specifically formulated for dynamic analysis. Such advanced tools are not usually readily available in engineering practice and the calibration and analysis of the computational models can be time consuming. The use of finite element pseudo-static analysis can be a good compromise between simplified methods of analysis and time domain analysis and consequently is widely used in engineering practice. The pseudo-static FE approach can accurately model the in-situ stresses prior to seismic loading (when it follows a static analysis simulating the construction sequence) is relatively simple and not as computationally expensive as the time domain approach.

Despite its simplicity and the plethora of relevant studies (e.g. Woodward \& Griffiths 1996, Li 2007, Tan \& Sarma 2008, Loukidis et al 2003), there are still a number of issues related to the pseudo-static finite element approach, and in particular the dependence of the solution on the mesh size, which have not been addressed adequately in the literature. This paper attempts to clarify some of the limitations of pseudo-static FE analysis using two simple examples; a homogeneous slope and an excavation next to a cantilever wall, but most of the issues raised are relevant to other applications of the pseudo-static methodology.

\subsection{Pseudo-static finite element analysis}

Pseudo-static finite element analysis is used to evaluate the seismic response of various types of geotechnical structures such as retaining walls, embankments, dams, tunnels. Depending on the type and geometry of the problem two approaches of pseudo-static analysis can be followed:

- Force based analysis. In this case, the seismically induced inertia forces are approximated as a constant body force (in one or two directions) which is applied incrementally throughout the whole mesh (see Figure 1a): 


$$
\begin{aligned}
& F_{h}=k_{h} \mathrm{~W} \\
& F_{v}=k_{v} \mathrm{~W}
\end{aligned}
$$

where $F_{h}, F_{v}$ are the horizontal and vertical body forces respectively, $k_{h}, k_{v}$ are the corresponding seismic coefficients and $W$ is the weight of the failure mass. The main objective of the analysis is either to determine the critical acceleration $\left(\mathrm{k}_{\mathrm{c}} \mathrm{g}\right)$ for which the structure fails or to determine the Factor of Safety for the design acceleration level.

- Deformation based analysis. In this case, the mesh is subjected to simple shear conditions, as schematically illustrated in Figure 1b. A uniform displacement, $u_{s}$, and a triangular displacement distribution, are applied incrementally along the top and the lateral boundaries of the mesh respectively. For the calculation of the displacement $u_{s}$ a site response analysis is performed first which determines the maximum free-field shear strain $\left(\nu_{\mathrm{ff}}\right)$ at the level corresponding to the structure of interest (see Figure 1b).

The deformation based analysis simulates more realistically the seismic loading as the imposed deformation is based on a site response analysis which takes into account the dynamic response of the stratigraphy to a time-varying ground motion. However this approach can only be used for problems in which it is possible to impose simple shear conditions to the mesh (mainly seismic analysis of underground structures, e.g. Hashash et al 2005, Kontoe et al 2008, Avgerinos \& Kontoe 2011) and it cannot be used to calculate the factor of safety or the critical failure mode. Therefore, for most problems, the force based approach is followed. The aim of the present study is to highlight some common pitfalls related to the use of the forced-based approach by analysing two simple problems investigating the dependence of the solution on the mesh width.

\subsection{Homogeneous layer failure mechanism}

Before examining the slope and the retaining wall examples, it is important to establish the failure mechanism which is imposed by the force based approach in a greenfield profile. Therefore the first problem analysed consists of a simple homogeneous soil layer of thickness DH overlaying perfectly rigid bedrock, which is subjected to an incremental horizontal body force. The objective of the exercise is to determine the critical horizontal yield acceleration coefficient, $k_{h}^{\text {lim }}$, for which the layer fails by sliding along the interface with the rigid bedrock. It will be shown in the following examples that this layer mechanism can be practically mobilised in any type of force based pseudo-static analysis and determines the limiting value of pseudo-static horizontal acceleration that can be reached. As suggested by Loukidis et al (2003), considering the limit equilibrium of a homogeneous soil profile of thickness DH overlying a rigid layer, the critical seismic coefficient, $k_{h}^{\text {lim }}$, required to balance the shear resistance at the interface is given by: 


$$
k_{h}^{l i m}=\frac{c}{\gamma \mathrm{DH}}+\tan \phi^{\prime}
$$

where $\gamma$ is the bulk unit weight of the soil, DH is the layer thickness and c, $\phi^{\prime}$ are the cohesion and the angle of shearing resistance respectively.

\subsubsection{Analysis arrangement}

The problem geometry and the adopted boundary conditions, restriction of movement in both directions along the bottom boundary and restriction of the horizontal displacement along the lateral boundaries, are schematically illustrated in Figure 2. In all the following analyses an initial stress field was assumed adopting the $K_{\circ}$ expression of Jaky (1944):

$$
\mathrm{K}_{\mathrm{o}}=1-\sin \phi^{\prime}
$$

The finite element mesh was constructed with 8 noded isoparametric quadrilateral elements and all the analyses presented herein were performed in plane strain with the finite element code ICFEP (Potts and Zdravkovic, 1999). The soil was assumed to be dry and was modelled using an associated Mohr-Coulomb failure criterion, while the behaviour is assumed to be isotropic linear elastic before failure. The adopted soil properties are detailed in Table 1 . The pseudo-static failure mechanism of the homogeneous soil layer was investigated by subjecting a layer $100 \mathrm{~m}$ wide and $12 \mathrm{~m}$ deep, using a fine discretization of 7500 square elements, to a gradually increasing body force.

\subsubsection{Failure mechanism}

Figure 3 shows the contours of sub-accumulated deviatoric plastic strain (from the excavation stage), $\Delta E_{p d}$ (see Equation 4), at the last stable increment of the analysis, for $\phi^{\prime}=20^{\circ}$, illustrating the soil layer failure mechanism which develops tangentially along the interface with the rigid bedrock and extends up to the right mesh boundary.

$$
\Delta E_{p d}=\frac{2}{\sqrt{6}} \sqrt{\left(\Delta \varepsilon_{p 1}-\Delta \varepsilon_{p 2}\right)^{2}+\left(\Delta \varepsilon_{p 2}-\Delta \varepsilon_{p 3}\right)^{2}+\left(\Delta \varepsilon_{p 3}-\Delta \varepsilon_{p 1}\right)^{2}}
$$

where $\Delta \varepsilon_{p 1}, \Delta \varepsilon_{p 2}, \Delta \varepsilon_{p 3}$ are the sub-incremental principal plastic strains from the excavation stage.

The FE analysis resulted in a $k_{\text {lim }}=0.463$, which is slightly higher than the limit equilibrium result of $k_{\text {lim }}=0.444$ based on Equation 2. This layer mechanism, although theoretically justified, has little physical meaning, as this type of failure has not been observed in post-earthquake reconnaissance investigations. The subsequent examples will demonstrate that this layer mechanism can be mobilised in any type of force based pseudo-static analysis. 


\subsection{Example of seismic slope stability analysis}

Having established the fundamental layer mechanism induced by the force based approach and the limiting value of the critical seismic coefficient for a simple homogeneous layer, it is important to examine its impact on a more realistic problem of seismic slope stability.

\subsubsection{Analysis arrangement}

A simple homogeneous dry slope is subjected to an incremental horizontal body force in order to determine the critical horizontal yield acceleration coefficient $k_{h}^{c}$ and the slope movements prior to failure. The problem geometry and the adopted boundary conditions are illustrated in Figure 4. The boundary conditions and material properties for this set of analysis were identical to the ones used for the homogeneous layer problem. Starting from level ground the stress field prior to the application of the seismic loading was established by excavating to form a $8 \mathrm{~m}$ high slope $(\mathrm{H}=8 \mathrm{~m})$. The element edge size was taken as $5 \%$ of the slope height (i.e. $0.4 \mathrm{~m}$ ) in the vicinity of the eventual failure surfaces, in order to simulate the failure mechanism with sufficient accuracy.

\subsubsection{Definition of slope failure mechanism and interaction with the mesh boundaries}

The first set of analyses concerns a parametric study in which the slope angle $\beta$ is varied $\left(\beta=20^{\circ}, 30^{\circ}\right.$ and $\left.45^{\circ}\right)$. The analysed slope geometries have a ratio $c / \gamma H=0.12, \phi=20^{\circ}$, $\mathrm{L}_{1}=\mathrm{L}_{2}=50 \mathrm{~m}$ and $\mathrm{D}=1.5$ and are taken to failure by gradually increasing the horizontal body force. Figure 5 compares the resulting failure mechanisms for the three cases, by plotting the sub-accumulated (from the end of excavation) contours of deviatoric plastic strain at the last stable increment of the analysis before failure. In all cases a slope failure mechanism can be depicted, but for the lowest slope angle $\left(\beta=20^{\circ}\right)$, in addition to the slope failure mechanism, a generalised failure mechanism develops which extends up to the right mesh boundary. In all three analyses there is strain concentration around the bottom and right boundaries, but clearly the severity of strain concentration increases as the slope angle reduces.

The contour plots of Figure 5 suggest that the right boundary of the mesh interferes with the failure mechanism, for the gently sloping cases, and thus it potentially affects the accuracy of the $k_{h}^{c}$ calculation. In addition, it is not clear from Figure 5 whether the resulting $k_{h}^{c}$ value corresponds to the slope or the generalised mechanism or to a combination of both. To further investigate this, the above set of analysis was repeated using a wider mesh taking the lateral boundary $100 \mathrm{~m}$ away from the slope toe. The plastic strain contour plots for this case (Figure 6) shows that the mesh boundary interferes with the failure mechanism only for the case of $\beta=20^{\circ}$. While the generalised mechanism starts developing for the case of $\beta=30^{\circ}$ it does not extend up to the lateral boundary suggesting that the length of $L_{2}=100 \mathrm{~m}$ is adequate for this analysis. Figure 7 plots the horizontal displacement at mid-height of the slope against the seismic coefficient $k_{h}$ for the various analyses. The mesh width has only a small impact on the predicted $k_{h}^{c}$ value for the $\beta=20^{\circ}$ slope, while it has no impact on the predicted $k_{h}^{c}$ for the remaining two slopes. Therefore if the desired design parameter from the analysis is the $k_{h}^{c}$ value, for the cases examined 
so far, the actual gain in accuracy from using a wider mesh is actually minimal. It should be clarified that in this study the horizontal movements are only plotted to identify the $\mathrm{k}_{\mathrm{h}}^{\mathrm{c}}$ values and should not be confused with the permanent ground displacements which can accumulate during seismic failure. The latter can only be estimated by time domain elastoplastic finite element analysis or sliding block models.

The $\mathrm{k}_{\lim }$ value of 0.463 for the previous example of the homogeneous soil layer can explain why the generalised layer mechanism is triggered only for the gentle sloping cases. The steepest slope (i.e. $\beta=45^{\circ}$ ) has obviously a much lower $k_{h}^{c}$ value than the other two slopes which is also considerably lower than the $k_{\lim }$ value. Therefore in this case, the slope mechanism develops fully before even the layer mechanism is triggered. On the other hand for the $\beta=20^{\circ}$ case the $k_{h}^{c}$ value is closer to the $k_{\text {lim }}$ value and the slope mechanism starts developing simultaneously with the layer mechanism making it difficult to distinguish the prevailing mechanism.

Loukidis et al (2003) refer to slope problems developing the layer failure mechanisms as singularity cases and note that these cases occur for large values of the stability factor $\lambda$, defined in their paper as:

$$
\lambda=\frac{c}{\gamma \mathrm{H} \tan \phi}
$$

To further investigate the observations of Loukidis et al (2003), the analysis for $\beta=45^{\circ}$, for which the layer mechanism did not develop, was repeated for $\phi^{\prime}=10^{\circ}$ and $\phi^{\prime}=30^{\circ}$ corresponding to $\lambda=0.681$ and 0.208 respectively. Figure 8 plots the sub-accumulated (from the end of excavation) contours of deviatoric plastic strain at failure for these two cases. The analysis for $\phi^{\prime}=10^{\circ}$ shows a clear slope mechanism developing, while the analysis for $\phi^{\prime}=30^{\circ}$ shows, apart from the slope failure, the development of the layer mechanism. Therefore for the examined cases herein the opposite trend was observed, since the singularity develops for the analysis with the lower stability factor. This can be explained again based on the computed $k_{h}^{c}$ values in comparison with the $\mathrm{k}_{\text {lim }}$ value. The $\phi^{\prime}=10^{\circ}$ analysis has a considerably lower $k_{h}^{c}(=0.047)$ value than the layer $k_{\lim }(=0.256$, from Eq.2) value, while the $k_{h}^{c}$ value for the $\phi^{\prime}=30^{\circ}$ analysis $(=0.418)$ lies closer to the corresponding $\mathrm{k}_{\lim }$ value ( $=0.657$ from Eq.2). Hence for the $\phi^{\prime}=10^{\circ}$ analysis the slope fails before the layer mechanism is triggered, while for the $\phi^{\prime}=30^{\circ}$ analysis the two mechanisms develop simultaneously. The results of the present study show that the dominant factor for the development of the layer mechanism is not the stability factor, but the relative magnitude of the $k_{h}^{c}$ and $\mathrm{k}_{\lim }$ values.

\subsubsection{Effect of the depth factor}

All the analyses presented so far have been carried out for slopes within a relatively shallow soil layer $(\mathrm{DH}=12 \mathrm{~m})$. Based on Equation 3 , the $\mathrm{k}_{\lim }$ of the soil layer mechanism depends on the depth of the homogeneous layer. It is therefore of interest to explore the interaction of the layer mechanism with the slope mechanism for deeper layers. Hence the previous set of analysis for a $8 \mathrm{~m}$ high slope was repeated for two additional depth factors, $\mathrm{D}=3.0$ and $\mathrm{D}=5.0$ and the resulting $k_{h}^{c}$ values are summarized in Table 2 . As for the lower depth factor, the width of the mesh does not significantly affect the predicted $k_{h}^{c}$ 
values and small differences between the $L_{2}=50 \mathrm{~m}$ and the $L_{2}=100 \mathrm{~m}$ analyses are only observed for slopes with $\beta=20^{\circ}$. In addition, the depth factor itself only affects the very gentle slope of $\beta=20^{\circ}$ where the $k_{h}^{c}$ value decreases with increasing depth factor. Although the differences in the resulting $k_{h}^{c}$ values are small, it should be noted that when the seismic coefficient $\left(k_{h}^{c}\right)$ is used as an input for a subsequent sliding block analysis, even small differences in $k_{h}^{c}$ can result in significant differences in terms of movements (Crespellani et al 1998, Li 2007). Furthermore Table 3 presents published $k_{h}^{c}$ values for various methods of analysis showing very good agreement with the results of the present study, especially for $L_{2}=100 \mathrm{~m}$.

Figures 9 and 10 plot the sub-accumulated (from the end of excavation) contours of deviatoric plastic strain at the last stable increment of the analysis before failure for $\beta=20^{\circ}$ and $\beta=45^{\circ}$ for $D=3.0$ and $D=5.0$ respectively. As for the case of $D=1.5$ the generalised mechanism develops only for the case of $\beta=20^{\circ}$, while for $\beta=45^{\circ}$ there is some strain concentration on the right boundary but without the development of the full layer mechanism. Based on the above and in accordance with Loukidis et al (2003), it can concluded that for the cases where the slope mechanism develops first (i.e. $\beta=30^{\circ}$ and $\beta=45^{\circ}$ ) the $k_{h}^{c}$ vale is insensitive both to the distance of the lateral boundary and to the depth factor. This is also seen in Table2, where the values of $k_{h}^{c}$ depend on the depth factor only for $\beta=20^{\circ}$.

Figure 11 plots the horizontal displacement at mid-height of the slope against the seismic coefficient $k_{h}$ for $D=3.0$ and $D=5.0$. In contrast to the critical acceleration, the differences between the predicted displacements for the two mesh widths significantly increase as the depth factor increases. While for the case of $D=1.5$ the differences in the predicted displacements were mainly just prior to failure and for $\beta=20^{\circ}$, for the larger depth factors the width of the mesh affects the predicted displacements for all slope angles and for the entire range of $k_{h}$ values. The $L_{2}=50 \mathrm{~m}$ mesh gives consistently lower movements, which for $D=5.0$ and $\beta=20^{\circ}$ just prior to failure is $35.0 \%$ lower than that predicted by the $L_{2}=100 \mathrm{~m}$ analysis.

\subsection{Example of seismic retaining wall analysis}

\subsubsection{Analysis arrangement}

The second example refers to a pseudo-static analysis of a simple cantilever retaining wall, which is schematically illustrated in Figure 12. The aim of this set of analysis is to investigate whether the problem identified in the slope analysis, regarding the development of the layer failure mechanism, is restricted to slope stability problems or whether it has wider implications to other types of problem when subjected to pseudostatic forces. For consistency with the previous example, the same soil properties and constitutive behaviour were assumed, while the wall was modelled as an elastic material with solid elements which were assigned the properties listed in Figure 12. The wall was wished in place and the initial stress field was established by excavation from level ground 
to form an $8 \mathrm{~m}$ deep cutting and in a homogeneous soil layer of thickness $\mathrm{DH}=40 \mathrm{~m}$ overlaying perfectly rigid bedrock. Subsequently, the wall was taken to failure by gradually increasing the horizontal body force.

\subsubsection{Interaction with the mesh boundaries}

For the first analysis of the cantilever wall with $\phi^{\prime}=20^{\circ}$, the right boundary of the mesh was placed at a distance $L_{2}=50 \mathrm{~m}$ from the wall (Figure 13a). The resulting contours of sub-accumulated (from the end of excavation) deviatoric plastic strain at failure show that the active mechanism extends up to the right mesh boundary, while, once more, a layer failure mechanism is depicted developing tangentially from the bottom mesh boundary and extending up to the right boundary. Furthermore the strain contours of Figure 13a suggest that the active wall failure mechanism interacts with the layer mechanism making it difficult to distinguish the prevailing mechanism. The analysis was then repeated moving the right boundary further away from the wall to a distance of $\mathrm{L}_{2}=100 \mathrm{~m}$. The corresponding contour plots for this case (Figure $13 \mathrm{~b}$ ) show that the two mechanisms are more distinct and that the active wall failure mechanism can be depicted more clearly. It is interesting to note that once again the mesh width does not affect the predicted $k_{h}^{c}$ values as both analyses gave almost identical $k_{h}^{c}$ values ( $k_{h}^{c}=0.373$ for $\mathrm{L}_{2}=50 \mathrm{~m}$ and $k_{h}^{c}=0.374$ for $\mathrm{L}_{2}=100 \mathrm{~m}$ ). Considering that the corresponding $\mathrm{k}_{\text {lim }}$ value based on Equation 2 is 0.388 , it is not surprising that the layer mechanism is so pronounced.

To further investigate the argument that the dominant factor for the development of the layer mechanism is the relative magnitude of the $k_{h}^{c}$ and $\mathrm{k}_{\text {lim }}$ values, the retaining wall analysis was repeated for $\phi^{\prime}=10^{\circ}$ and $\phi^{\prime}=30^{\circ}$. The sub-accumulated deviatoric plastic strain contours of Figure 14 show the same trends as the ones observed for the slope analyses of Figure 8 . Once more, the $\phi^{\prime}=10^{\circ}$ analysis has a lower $k_{h}^{c}(=0.135)$ value than the layer $\mathrm{k}_{\lim }(=0.2$, based on Eq. 2$)$ value, while the $k_{h}^{c}$ value for the $\phi^{\prime}=30^{\circ}$ analysis $(=0.61)$ lies very close to the corresponding $\mathrm{k}_{\lim }$ value $(=0.601$, based on Eq. 2$)$. Hence for the $\phi=10^{\circ}$ analysis the slope fails before the layer mechanism is developed, while for the $\phi=30^{\circ}$ analysis the two mechanisms develop simultaneously.

Figure 15a plots the horizontal wall movement just prior to failure and shows that the analysis with the smaller mesh predicts significantly lower movements. However these differences are mainly related to a rigid body movement of the wall (i.e. there is no significant variation in the predicted deflected shape of the wall) and thus they do not result in considerable differences in the induced wall stresses (not shown herein for brevity). Figure 15b plots the evolution of the horizontal displacement of the top of wall with $k_{h}$ indicating that the mesh width affects the predicted movements not only close to failure, but even for low values of $k_{h}$.

\subsection{Conclusions}

Pseudo-static finite element analysis has been widely used in engineering practice for the seismic design of geotechnical structures, as it is not as complicated or time 
consuming as full time-domain dynamic analysis. However this method should be used with caution as the results can be sensitive to the choice of the mesh dimensions. In this paper two simple examples of pseudo-static finite element analysis were examined parametrically, a homogeneous slope and a cantilever retaining wall, aiming to explore the sensitivity of the pseudo static analysis results to the adopted mesh size. Several conclusions regarding the applicability of pseudo-static analysis can be drawn from the examined examples:

- The analyses showed that a layer mechanism can be triggered and that this mechanism interferes with the slope failure mechanism or the active wall failure mechanism and the mesh boundaries. The development of the layer mechanism, while theoretically justified, is not realistic as such types of failure have not been observed in the field.

- The triggering or not of the layer mechanism in the analysis was shown to depend on the relative magnitude of the seismic coefficient $\left(k_{h}^{c}\right)$ and the layer seismic coefficient $\left(\mathrm{k}_{\mathrm{lim}}\right)$ both for the slope and the retaining wall analyses.

- In accordance with Loukidis et al (2003), it was found that for the cases where the slope mechanism develops first the $k_{h}^{c}$ value is insensitive both to the distance of the lateral boundary and to the depth factor.

- Comparison of analyses with different mesh widths, for both types of problem, showed that the triggering of the layer mechanism has a small impact on the predicted seismic coefficient $\left(k_{h}^{c}\right)$, but it can significantly affect the predicted movements. It should be highlighted though, that when the seismic coefficient $\left(k_{h}^{c}\right)$ is used as an input for a subsequent sliding block analysis, even small differences in $k_{h}^{c}$ can result in significant differences in terms of movements.

- The results of this study show that pseudo- static FE analysis is a useful tool in estimating the seismic coefficient. However, when the seismic coefficient $\left(k_{h}^{c}\right)$ is expected to have similar magnitude to the layer seismic coefficient $\left(k_{\lim }\right)$ the effects of the lateral boundaries should be carefully monitored and the mesh size should be accordingly adjusted. On the other hand, pseudo- static FE analysis should not be used for the estimation of movements; either a sliding block type of analysis or a full dynamic FE analysis should be used to estimate movements.

\subsection{Acknowledgements}

The authors are grateful for the anonymous reviews of this paper which helped to improve the clarity and completeness of the manuscripts considerably.

\subsection{References}

1. Avgerinos V. \& Kontoe S. (2011) "Modelling the ovalisation of circular tunnels due to seismic loading using different approaches", 5th International Conference on Earthquake Geotechnical Engineering, Santiago, Chile, No. MTOKO.

2. Crespollani, T., Madiai, C. \& Vannucchi G. (1998) "Earthquake destructiveness potential factor and slope stability". Geotechnique, Vol.48, No.3, pp. 411-419. 
3. Hashash Y.M.A., Park D. \& Yao J.I-C., (2005) "Ovaling deformations of circular tunnels under seismic loading, and update on seismic design and analysis of underground structures", Tunnelling and Underground Space Technology, Vol.20, pp. 435-441.

4. Jaky, J. (1944), "The coefficient of earth pressure at rest", J. Soc. Hungarian Arch. Engrs, Vol. 25, pp. 355-358.

5. Kontoe S., Zdravkovic L., Potts D.M \& Menkiti C.O. (2008) "Case study on Seismic Tunnel Response", Canadian Geotechnical Journal, Vol. 45, No.12, Pages: $1743-1764$.

6. Li, X. (2007), "Finite element analysis of slope stability using a nonlinear failure criterion", Computers \& Structures, Vol.34, pp.127-136.

7. Loukidis D., Bandini R. \& Salgado R. (2003), "Stability of seismically loaded slopes using limit analysis" Geotechnique, Vol. 53, No. 5, pp. 463-479.

8. Potts D.M. \& Zdravkovic L.T. (1999), "Finite element analysis in geotechnical engineering: theory", Thomas Telford, London.

9. Tan D. \& Sarma S. (2008), "Finite element verification of an enhanced limit equilibrium method for slope analysis", Geotechnique, Vol. 58, No. 6, pp. 481-487.

10. Woodward P.K. \& Griffiths D.V. (1996), "Comparison of the pseudo-static and dynamic behaviour of retaining walls", Geotechnical and Geological Engineering. Vol.14, pp. 269-290. 


\subsection{Figures}

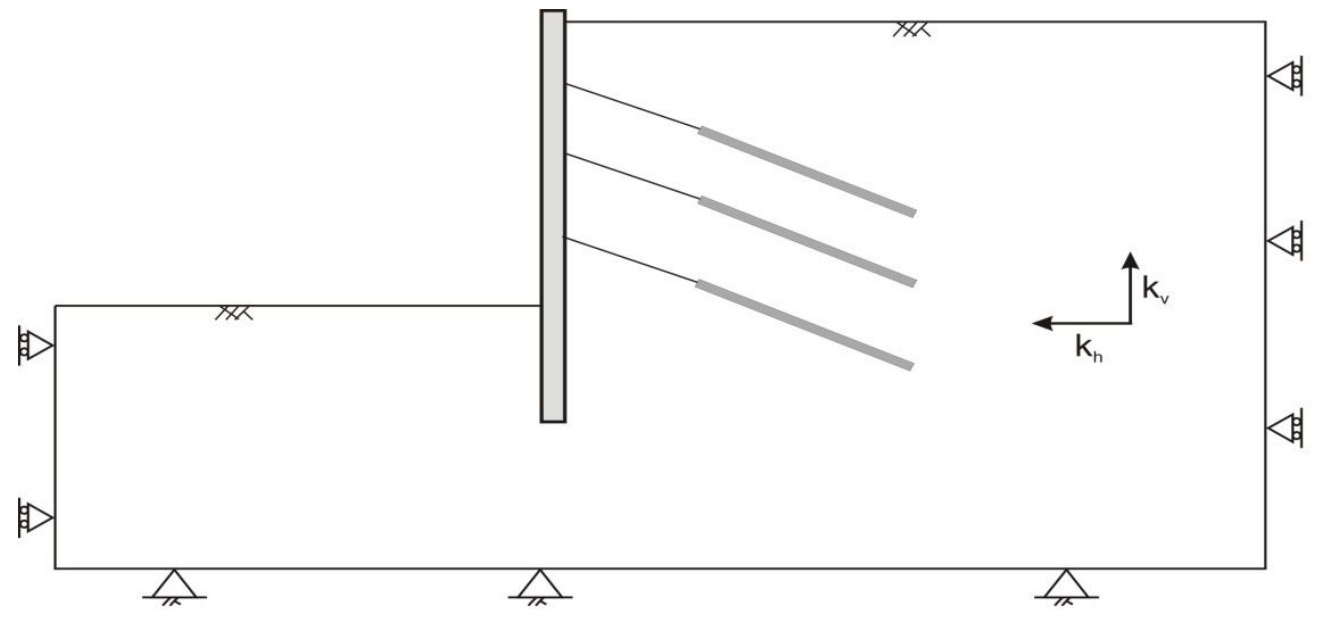

(a) Force based approach

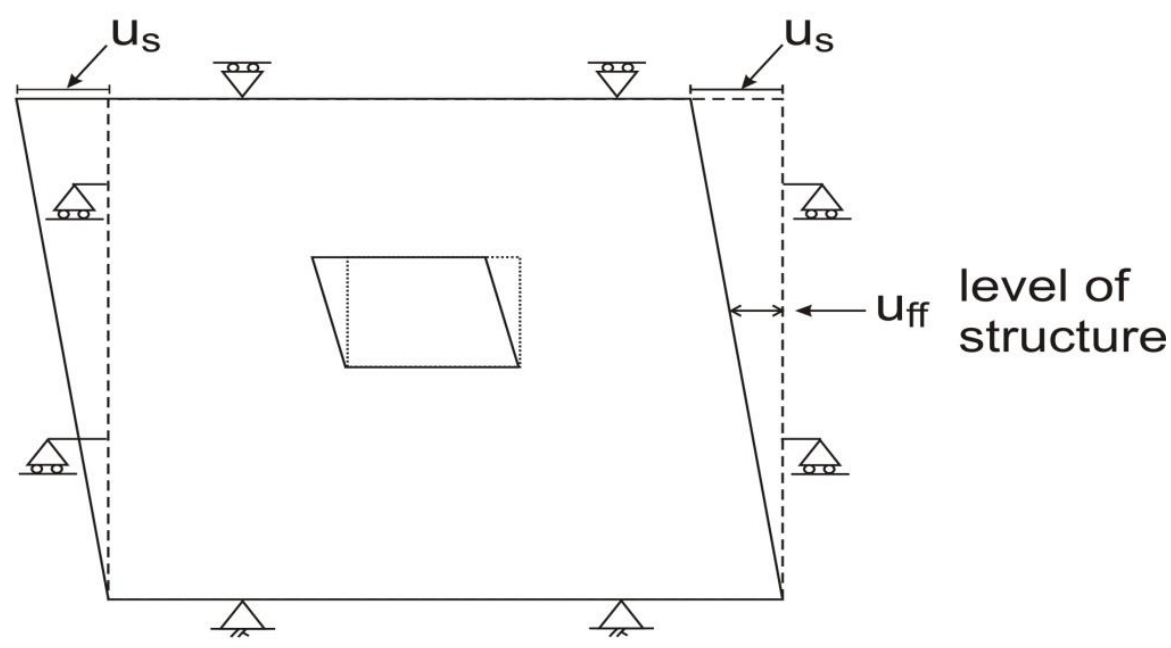

(b) Deformation based approach

Figure 1: Schematic representation of FE mesh configuration in pseudo-static analysis; (a) force based approach and (b) deformation based approach, where $u_{\mathrm{ff}}$ is the maximum free-field displacement at the level of the structure and $u_{s}$ is the displacement applied at the top boundary of the mesh

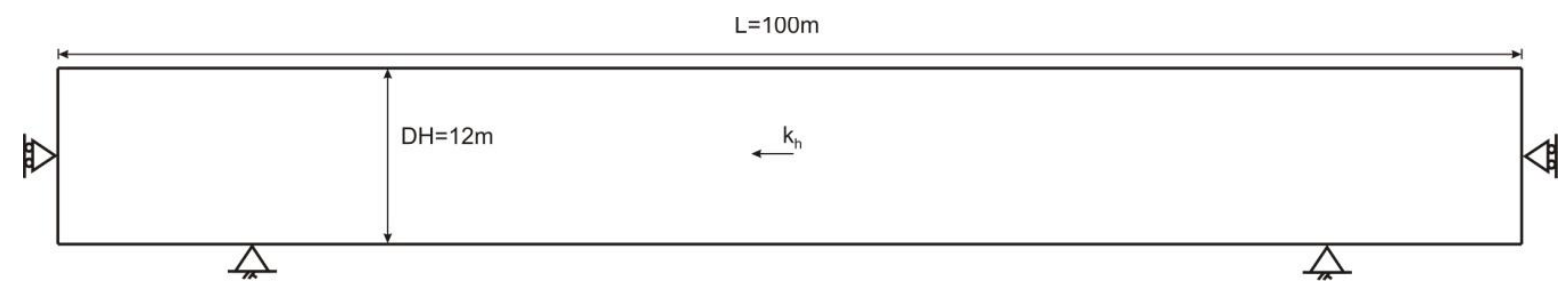

Figure 2: Problem arrangement and boundary conditions used in FE analysis for the homogeneous layer case. 


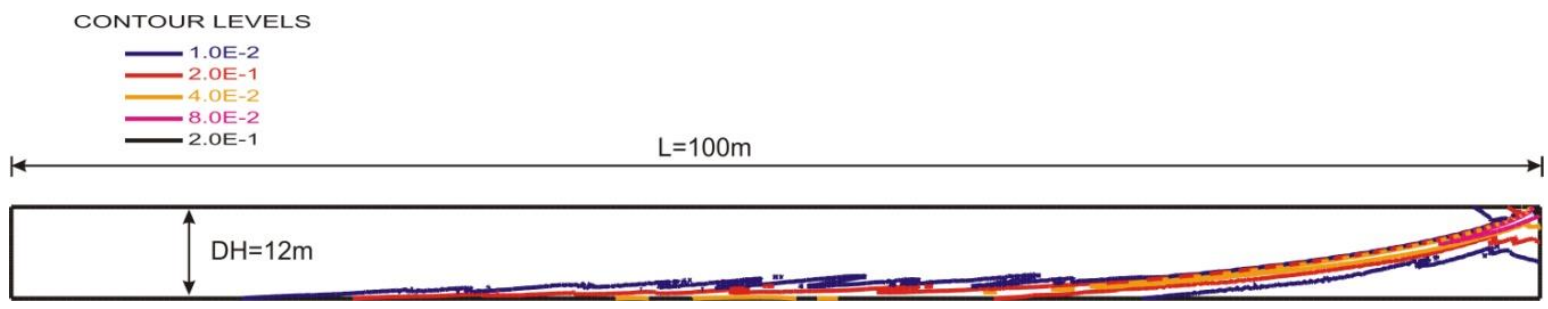

Figure 3: Contours of accumulated plastic deviatoric strain just prior to failure, for the homogeneous soil layer case.

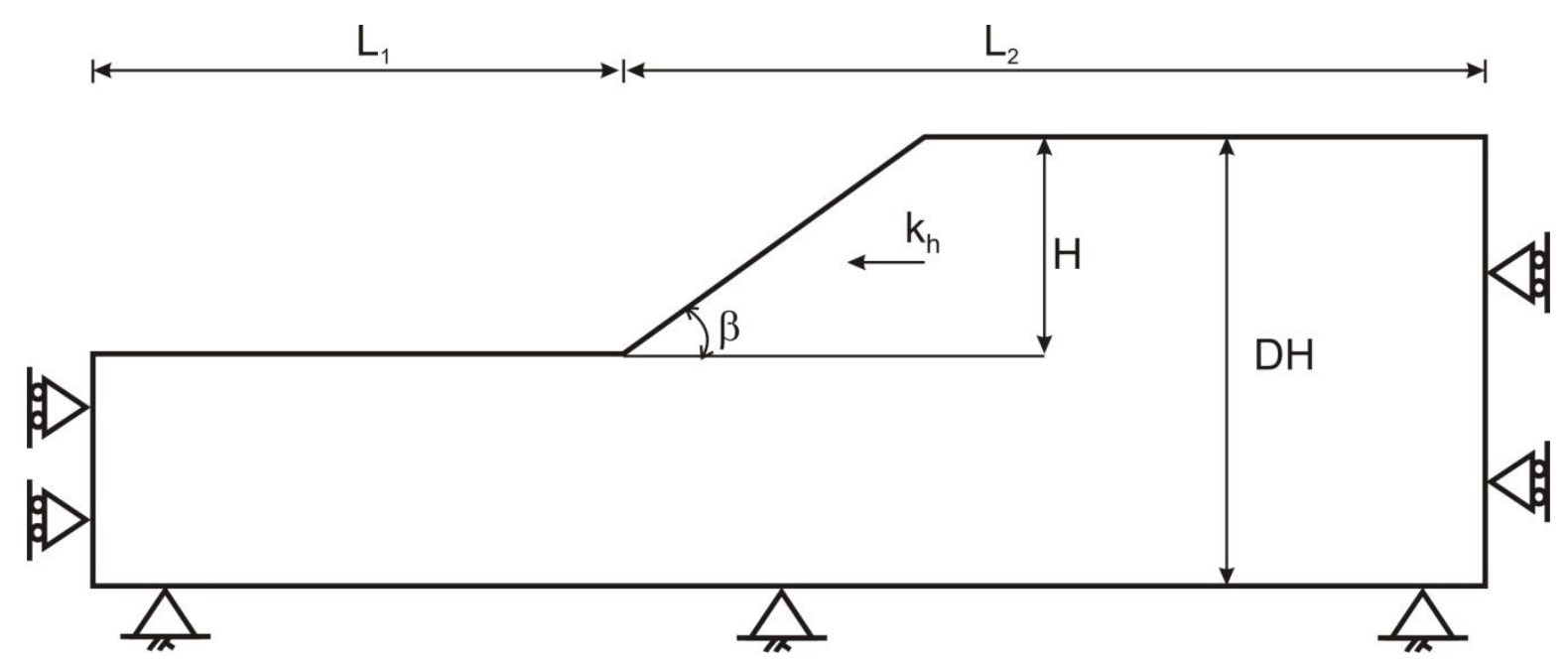

Figure 4: Problem arrangement and boundary conditions used in FE analysis. 


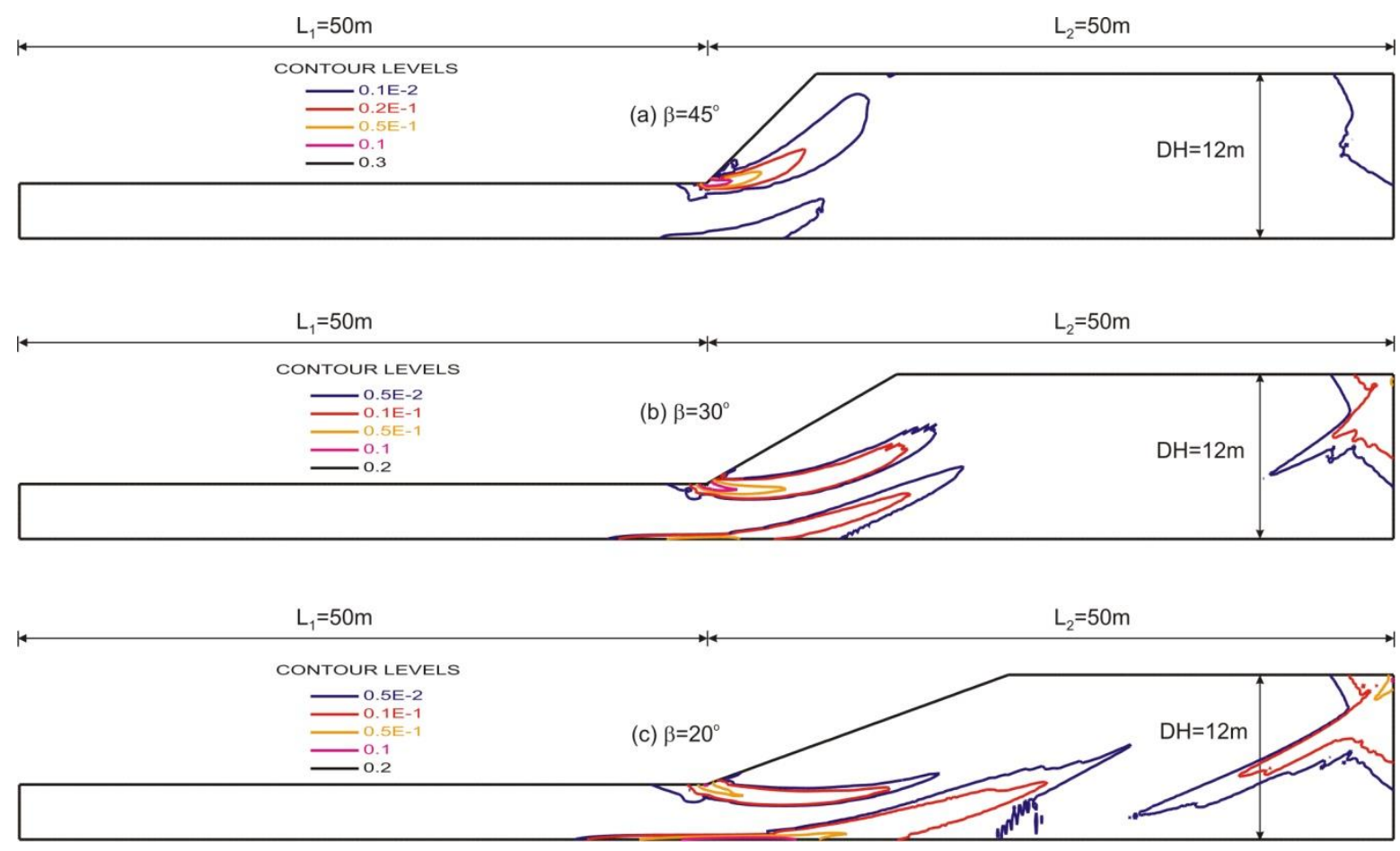

Figure 5: Contours of sub-accumulated (from the end of excavation) plastic deviatoric strain just prior to failure, for $D=1.5, L_{2}=50 \mathrm{~m}$ and 3 slope angles $\left(\beta=45^{\circ}, 30^{\circ} \& 20^{\circ}\right)$.
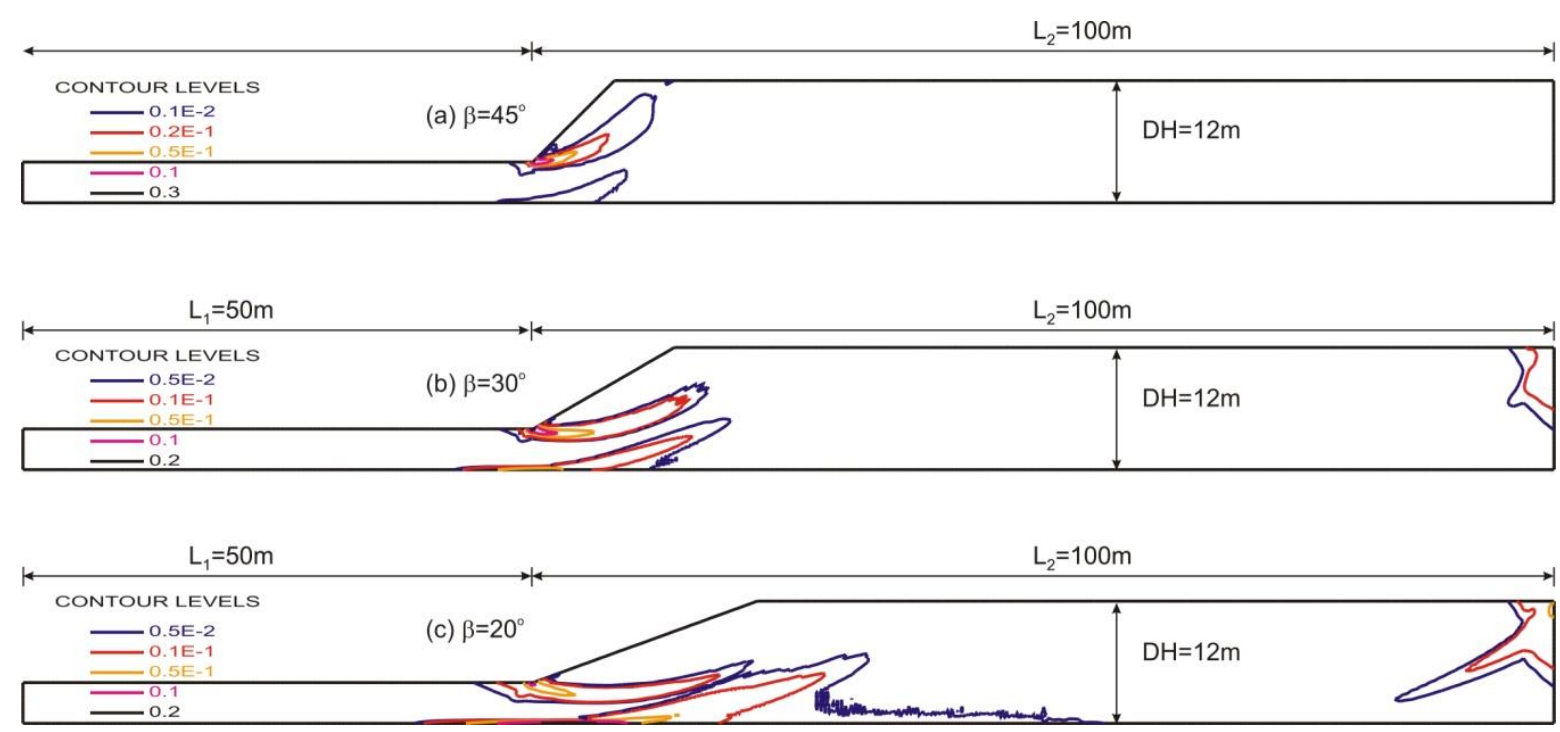

Figure 6: Contours of sub-accumulated (from the end of excavation) plastic deviatoric strain just prior to failure, for $D=1.5, L_{2}=100 \mathrm{~m}$ and 3 slope angles $\left(\beta=45^{\circ}, 30^{\circ} \& 20^{\circ}\right)$. 


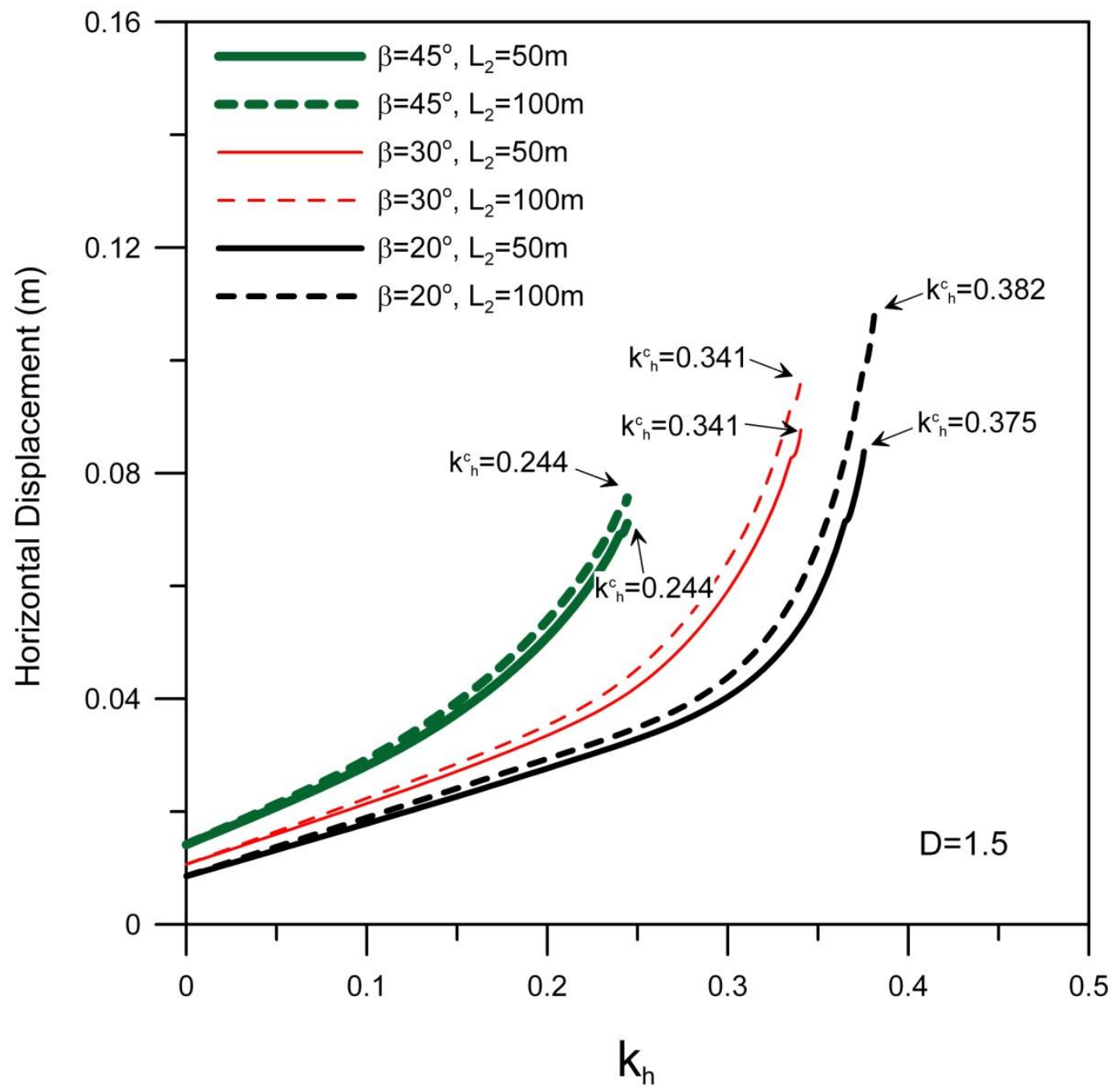

Figure 7: Horizontal displacement at the mid-height of the slope versus seismic coefficient $k_{h}$ for $D=1.5$. 

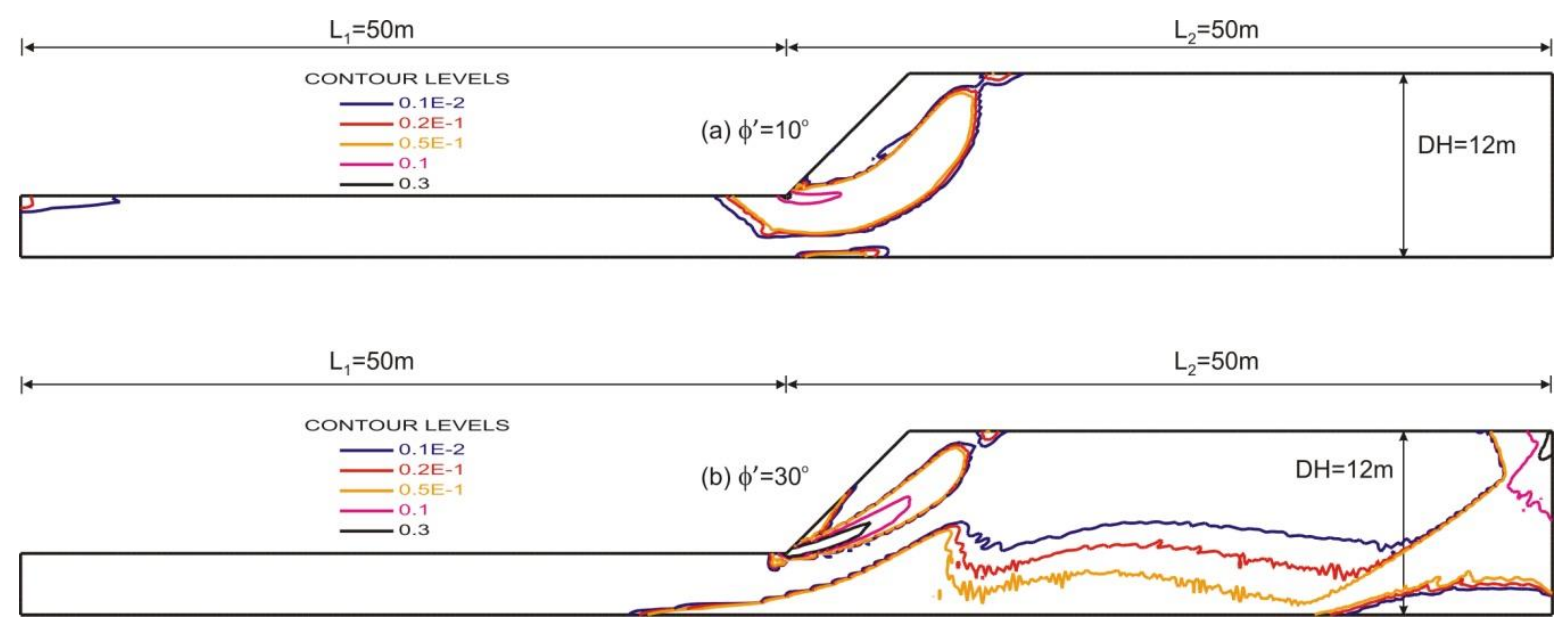

Figure 8: Contours of sub-accumulated (from the end of excavation) deviatoric plastic strain just prior to failure for a) $\phi^{\prime}=10^{\circ}$ and b) $\phi^{\prime}=30^{\circ}\left(D=1.5, \beta=45^{\circ}, L_{2}=50 \mathrm{~m}\right)$.
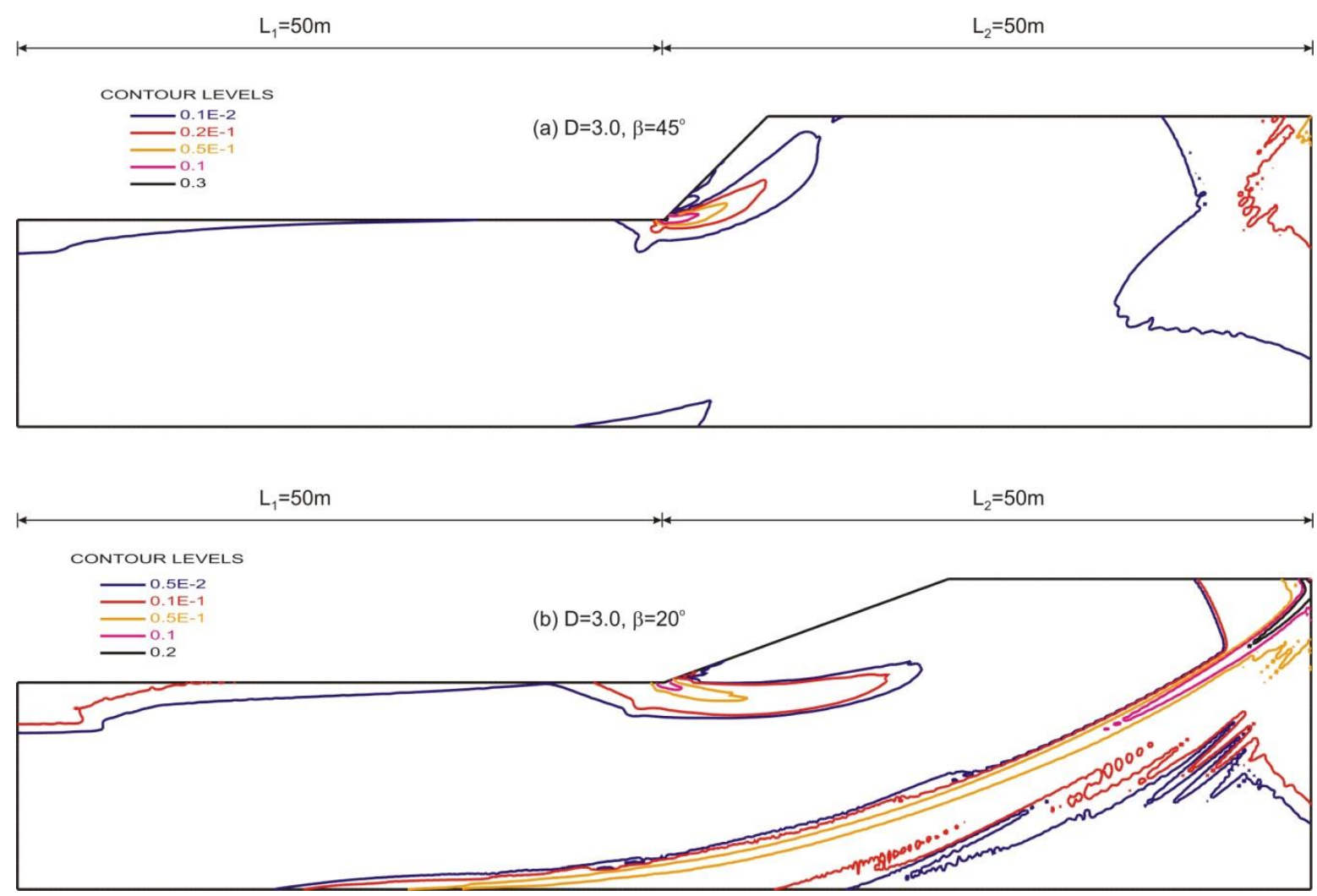

Figure 9: Contours of sub-accumulated (from the end of excavation) plastic deviatoric strain just prior to failure, for (a) $\beta=45^{\circ}$ and (b) $\beta=20^{\circ}\left(D=3.0, L_{2}=50 \mathrm{~m}\right)$. 

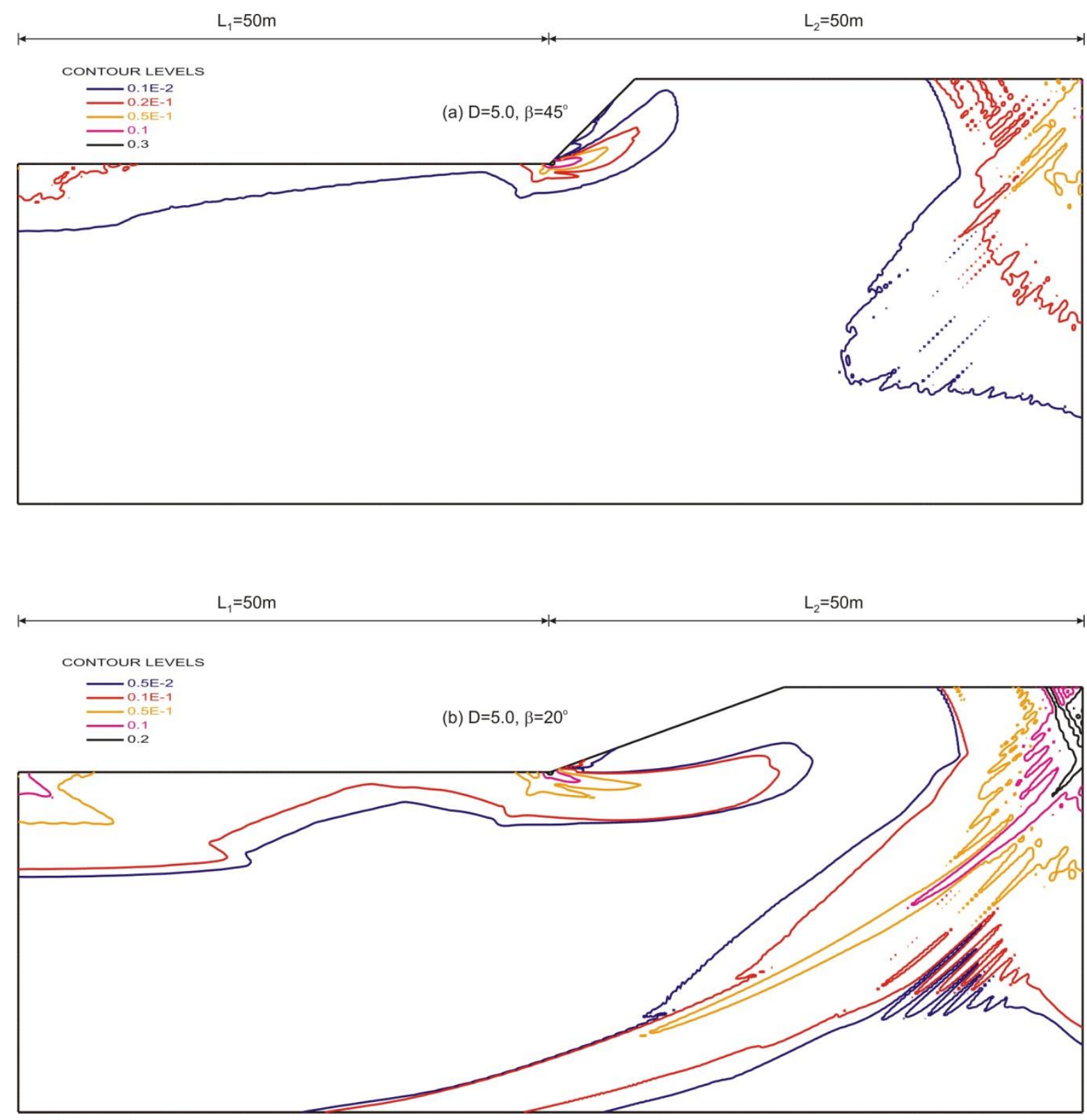

Figure 10: Contours of sub-accumulated (from the end of excavation) plastic deviatoric strain just prior to failure, for (a) $\beta=45^{\circ}$ and (b) $\beta=20^{\circ}\left(D=5.0, L_{2}=50 \mathrm{~m}\right)$ 

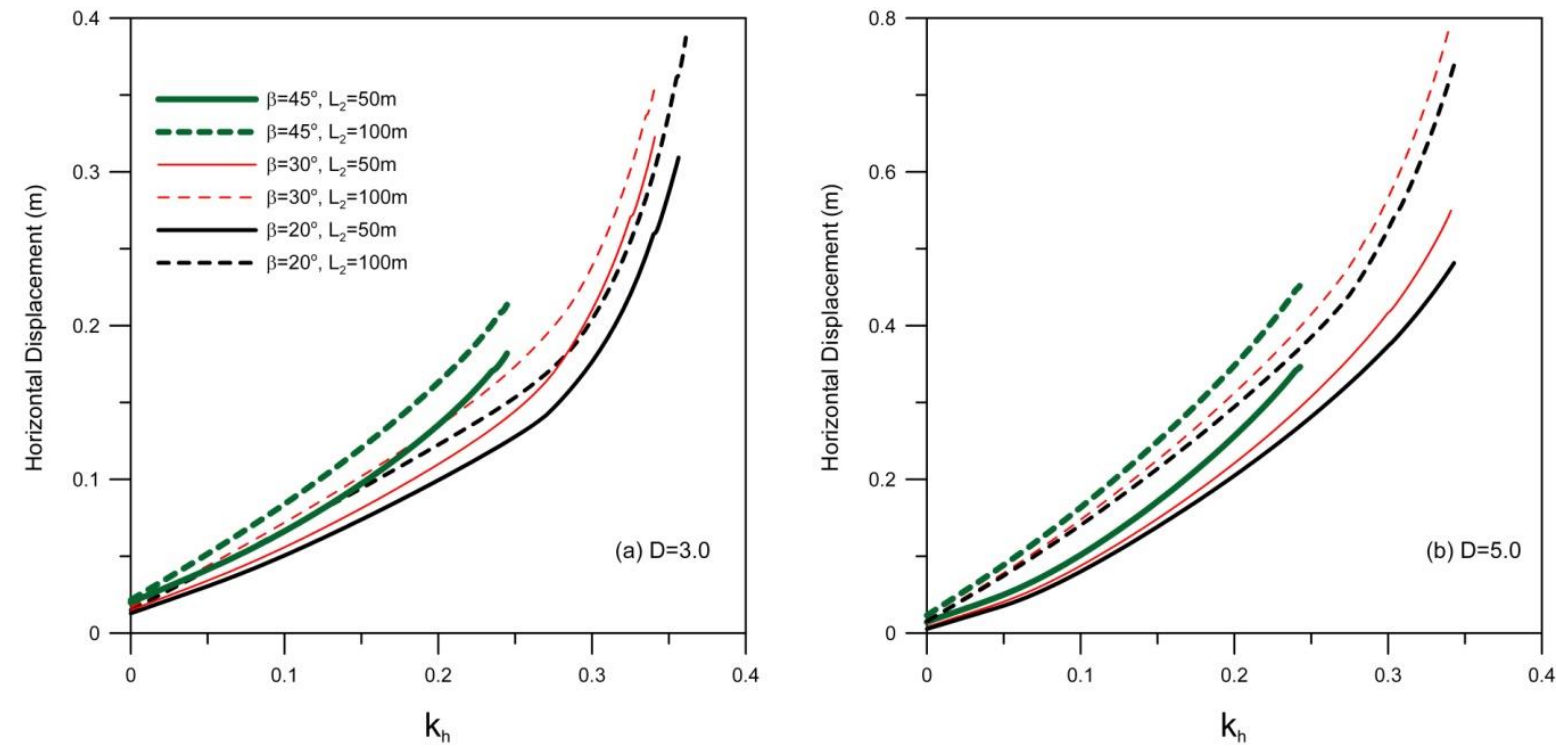

Figure 11: Horizontal displacement at the mid-height of the slope versus seismic coefficient $k_{h}$ for (a) $D=3.0$ and (b) $D=5.0$.

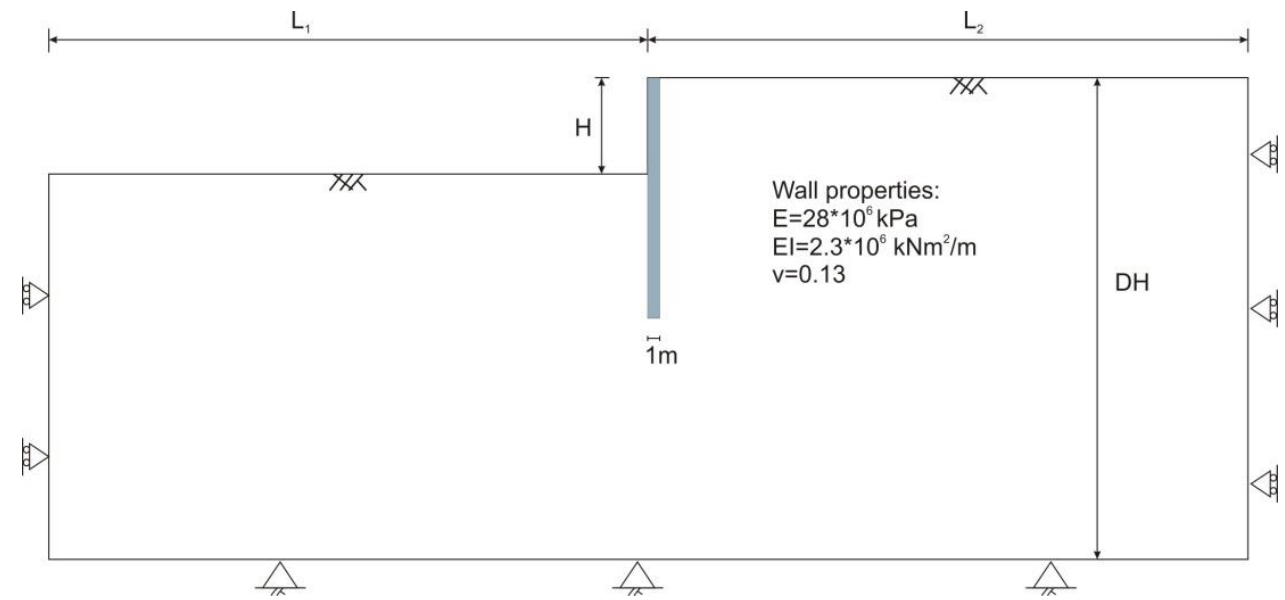

Figure 12: Problem arrangement and boundary conditions used in FE analysis. 


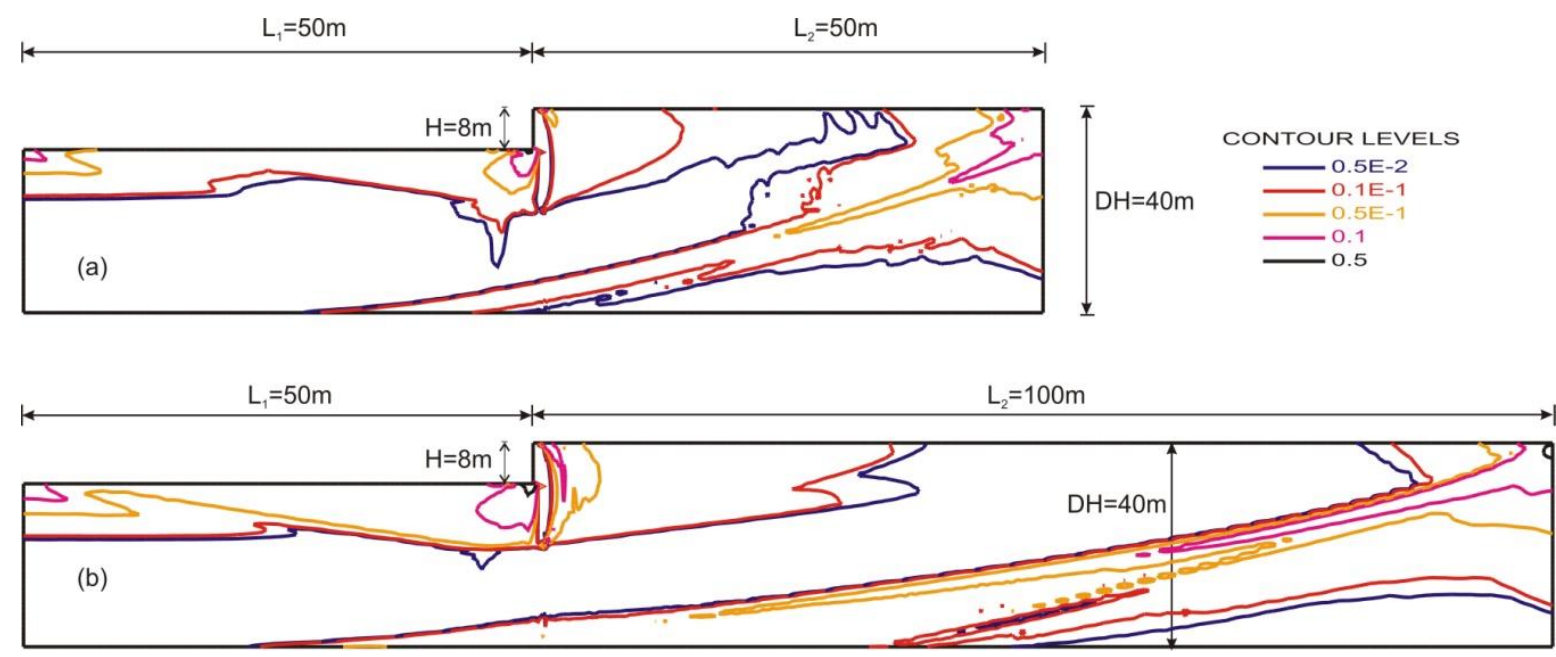

Figure 13: Contours of sub-accumulated (from the end of excavation) deviatoric plastic strain just prior to failure for the retaining wall problem for a) $L_{2}=50 m$ and $\left.b\right) L_{2}=100 m$

$$
\left(\phi^{\prime}=20^{\circ}\right) \text {. }
$$
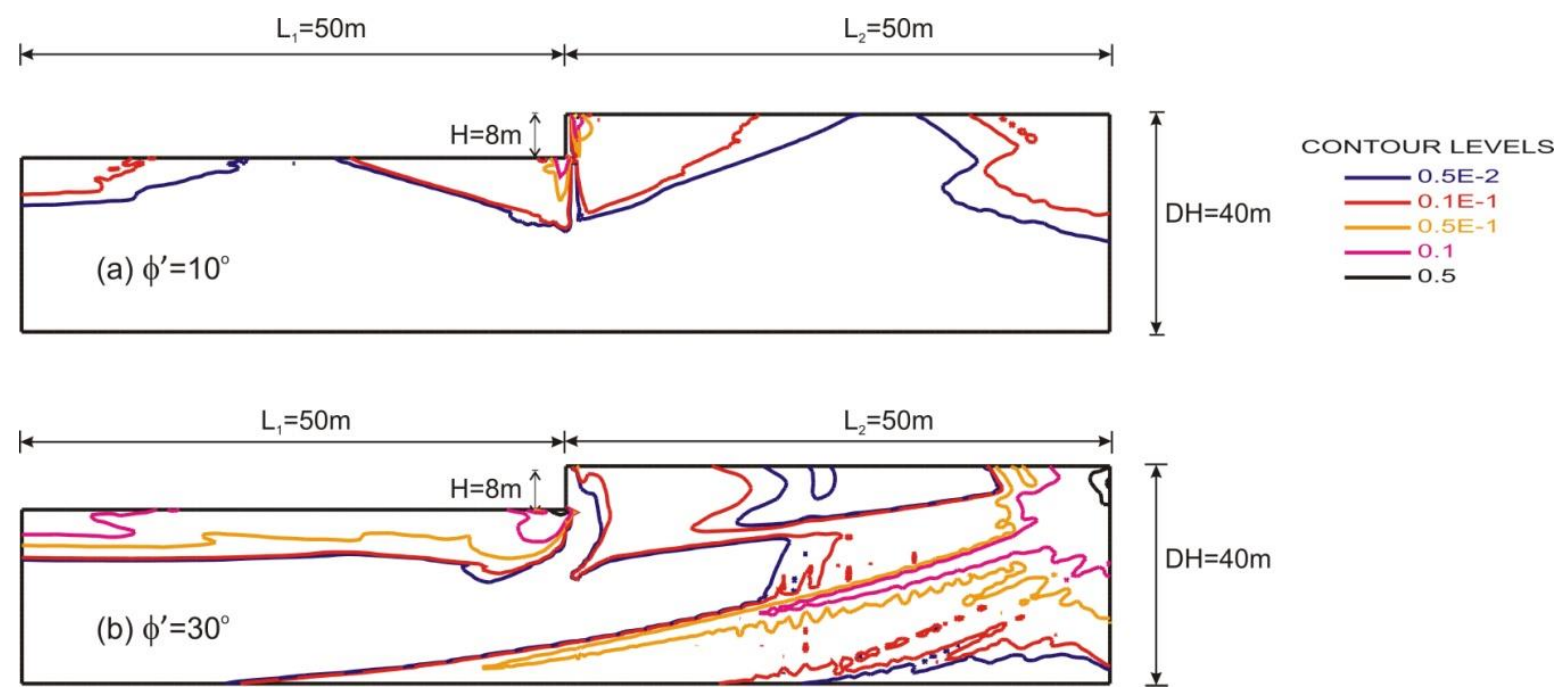

Figure 14 Contours of sub-accumulated (from the end of excavation) deviatoric plastic strain just prior to failure for the retaining wall problem for a) $\phi^{\prime}=10^{\circ}$ and b) $\phi^{\prime}=30^{\circ}$ $\left(\mathrm{L}_{2}=50 \mathrm{~m}\right)$. 

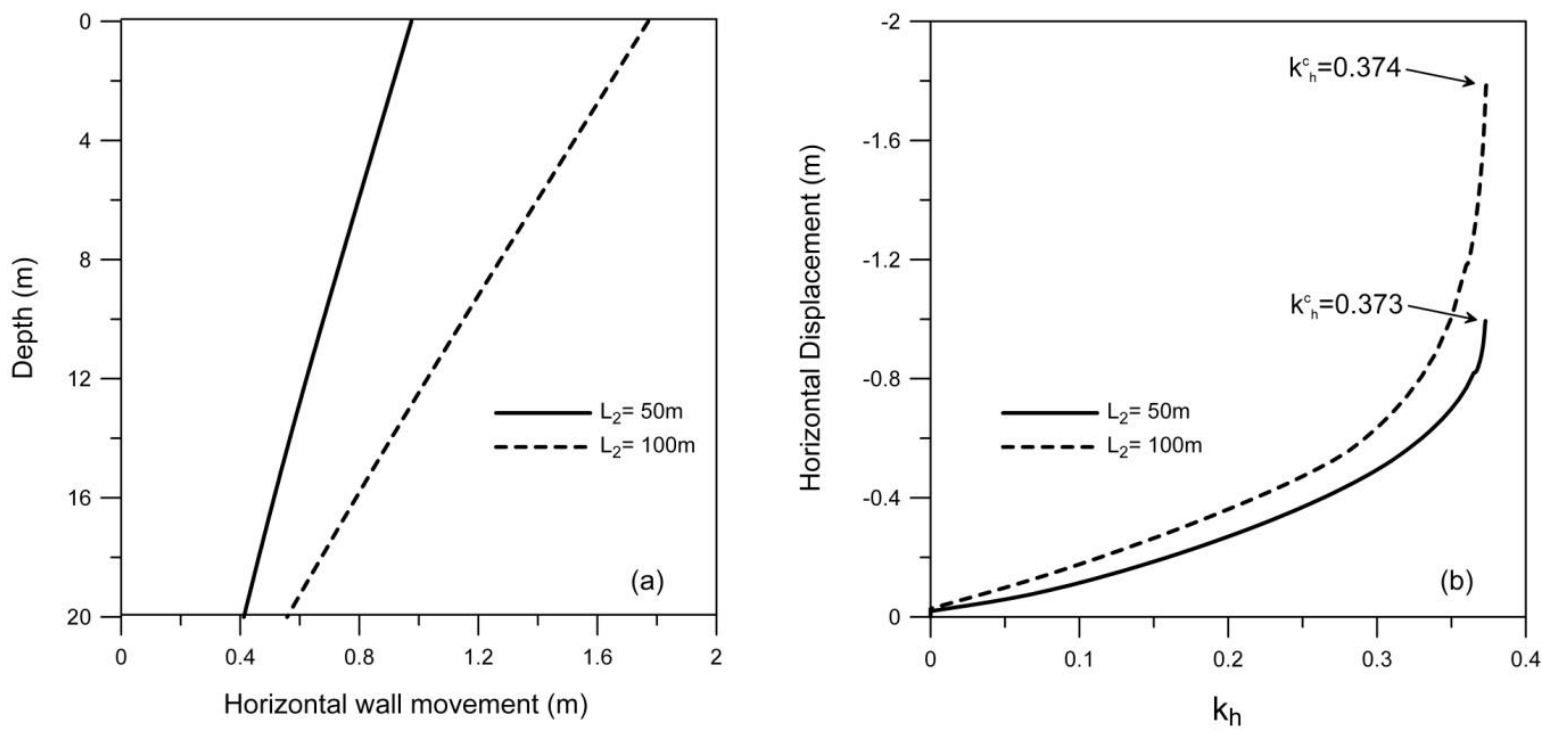

Figure 15: (a) Horizontal wall movement at failure and (b) horizontal displacement of the top of the wall versus seismic coefficient $k_{h}$.

\subsection{Tables}

Table 1: Material properties

\begin{tabular}{|l|l|}
\hline Youngs Modulus, $\mathrm{E}(\mathrm{MPa})$ & 20.0 \\
\hline Poisson ratio, $v$ & 0.33 \\
\hline Bulk unit weight $\left(\mathrm{kN} / \mathrm{m}^{3}\right)$ & 19.0 \\
\hline Cohesion, $\mathrm{c}^{\prime}(\mathrm{kPa})$ & 18.0 \\
\hline Angle of shearing resistance, $\phi^{\prime}\left(^{\circ}\right)$ & varied parametrically, 10, 20, 30 \\
\hline
\end{tabular}

Table 2: Summary of the calculated $\boldsymbol{k}_{\boldsymbol{h}}^{\boldsymbol{c}}$ values for the various slope analyses

\begin{tabular}{|c|r|r|r|r|r|r|}
\cline { 2 - 8 } \multicolumn{1}{c|}{} & \multicolumn{2}{c|}{$\beta=20^{\circ}$} & \multicolumn{2}{c|}{$\beta=30^{\circ}$} & \multicolumn{2}{c|}{$\beta=45^{\circ}$} \\
\hline $\begin{array}{c}\text { Depth } \\
\text { factor, } \\
D\end{array}$ & $\mathrm{~L}_{2}=50 \mathrm{~m}$ & $\mathrm{~L}_{2}=100 \mathrm{~m}$ & $\mathrm{~L}_{2}=50 \mathrm{~m}$ & $\mathrm{~L}_{2}=100 \mathrm{~m}$ & $\mathrm{~L}_{2}=50 \mathrm{~m}$ & $\mathrm{~L}_{2}=100 \mathrm{~m}$ \\
\hline 1.5 & 0.375 & 0.382 & 0.341 & 0.341 & 0.244 & 0.244 \\
\hline 3.0 & 0.356 & 0.361 & 0.341 & 0.341 & 0.244 & 0.244 \\
\hline 5.0 & 0.343 & 0.343 & 0.341 & 0.341 & 0.244 & 0.244 \\
\hline
\end{tabular}


Table 3: Summary of published $\boldsymbol{k}_{\boldsymbol{h}}^{\boldsymbol{c}}$ values for various methods of analysis

\begin{tabular}{|c|c|c|c|}
\hline Reference & $\beta=20^{\circ}$ & $\beta=30^{\circ}$ & $\beta=45^{\circ}$ \\
\hline $\begin{array}{c}\text { Loukidis et al. (2003) } \\
\text { Log-spiral Upper Bound } \\
\mathrm{D}=1.5\end{array}$ & 0.38 & 0.34 & 0.24 \\
\hline $\begin{array}{c}\text { Leshchinsky \& San (1994) } \\
\text { Limit Equilibrium }\end{array}$ & N/A & $0.344^{*}$ & 0.24 \\
\hline $\begin{array}{c}\text { Tan \& Sarma (2008) } \\
\text { Limit Equilibrium }\end{array}$ & $0.394^{*}$ & $0.355^{*}$ & N/A \\
\hline $\begin{array}{c}\text { Michalowski (2002) } \\
\text { Log-spiral Upper Bound }\end{array}$ & N/A & N/A & $0.238^{*}$ \\
\hline
\end{tabular}

*Values obtained by linear interpolation 